\title{
Promoting a new brain tumor mutation: TERT promoter mutations in CNS tumors
}

\author{
Zachary J. Reitman · Christopher J. Pirozzi · Hai Yan
}

Published online: 12 November 2013

(C) Springer-Verlag Berlin Heidelberg 2013

Genomic research has recently linked two fundamental observations about the molecular biology of cancer. The first of these pivotal observations is that cancer is essentially a genetic disease, with tumor cells driven to grow inappropriately by acquired genetic alterations that deregulate cellular molecular machinery. The second observation is that $\sim 85 \%$ of tumors contain upregulated activity of the ribonucleoprotein complex telomerase, which is thought to help tumor cells avoid senescence and achieve immortality by replenishing the telomere cap on the tips of chromatin. For many cancers, it remained unclear how telomerase activity came to be upregulated in the first place, with no obvious genetic cause to explain why telomerase activity was inappropriately "switched on". Now, recent work has uncovered what may very well be the genetic basis for telomerase activation in many human cancers, particularly CNS tumors. This work, including discoveries reported in three articles and one letter in this issue of Acta Neuropathologica, centers around recurrent point mutations in the promoter of the telomerase reverse transcriptase gene (TERT).

TERT promoter mutations were first identified in a whole-genome sequencing screen of melanomas and reported early in 2013 [7]. At the same time, similar mutations were discovered using a hereditary linkage approach in patients with familial melanomas [5]. Strikingly, the mutations were situated within the promoter of the TERT gene, rather than the protein-coding sequence, representing the first identification of a highly recurrent cancer mutation

Z. J. Reitman · C. J. Pirozzi · H. Yan $(\bowtie)$

The Department of Pathology and The Preston Robert Tisch Brain Tumor Center at Duke, Duke University Medical Center, Durham, NC 27710, USA

e-mail: yan00002@mc.duke.edu; hai.yan@dm.duke.edu outside the coding region of a gene. These discoveries in melanomas sparked a search for TERT promoter mutations in other cancer types. TERT promoter mutations were soon discovered in thyroid cancers, hepatocellular carcinomas, urinary epithelium tumors, and subtypes of sarcoma [9]. Such mutations turned out to be particularly prevalent in CNS tumors, occurring in a majority of glioblastomas and oligodendrogliomas, as well as in a portion of medulloblastomas and other CNS tumors [1, 9, 10, 13, 14].

In this issue, Nonoguchi and coworkers report TERT mutational status for 358 glioblastomas. They point out that TERT mutations occur in a majority of primary glioblastomas, i.e., tumors that arise de novo [13]. In contrast, the TERT mutations were rare among secondary glioblastomas, which develop slowly from lower-grade astrocytomas of WHO grade II-III, and which tend to contain IDHI mutations. While TERT mutations were associated with a poor prognosis among all glioblastoma patients, Nonoguchi and colleagues conclude this likely reflects their association with the poorer-performing primary glioblastomas.

Also in this issue, Koelsche and coworkers broaden the search for TERT promoter mutations to a wide variety of CNS tumor types by exploring a panel of 1,515 CNS tumors. They identify TERT mutations in rarer entities such as gliosarcomas $(81 \%)$ and solitary fibrous tumors $(50 \%)$ [10]. They also confirm that the TERT mutations are tightly correlated with $1 \mathrm{p} / 19 \mathrm{q}$ codeletion in oligodendrogliomas $[1,9,10]$ and mutually exclusive with $A T R X$ mutations and IDHI/IDH2 mutations in astrocytomas and glioblastomas.

In addition to gliomas, TERT mutations have been found to occur in $21 \%$ of medulloblastomas [14]. In an article by Remke and coworkers [14] in this issue, the clinical implications of TERT mutations in patients with this tumor type were explored in a cohort of 466 medulloblastoma patients. 
chromosome 5 , minus strand

$1,295,400-1,295,000$ (hg19)

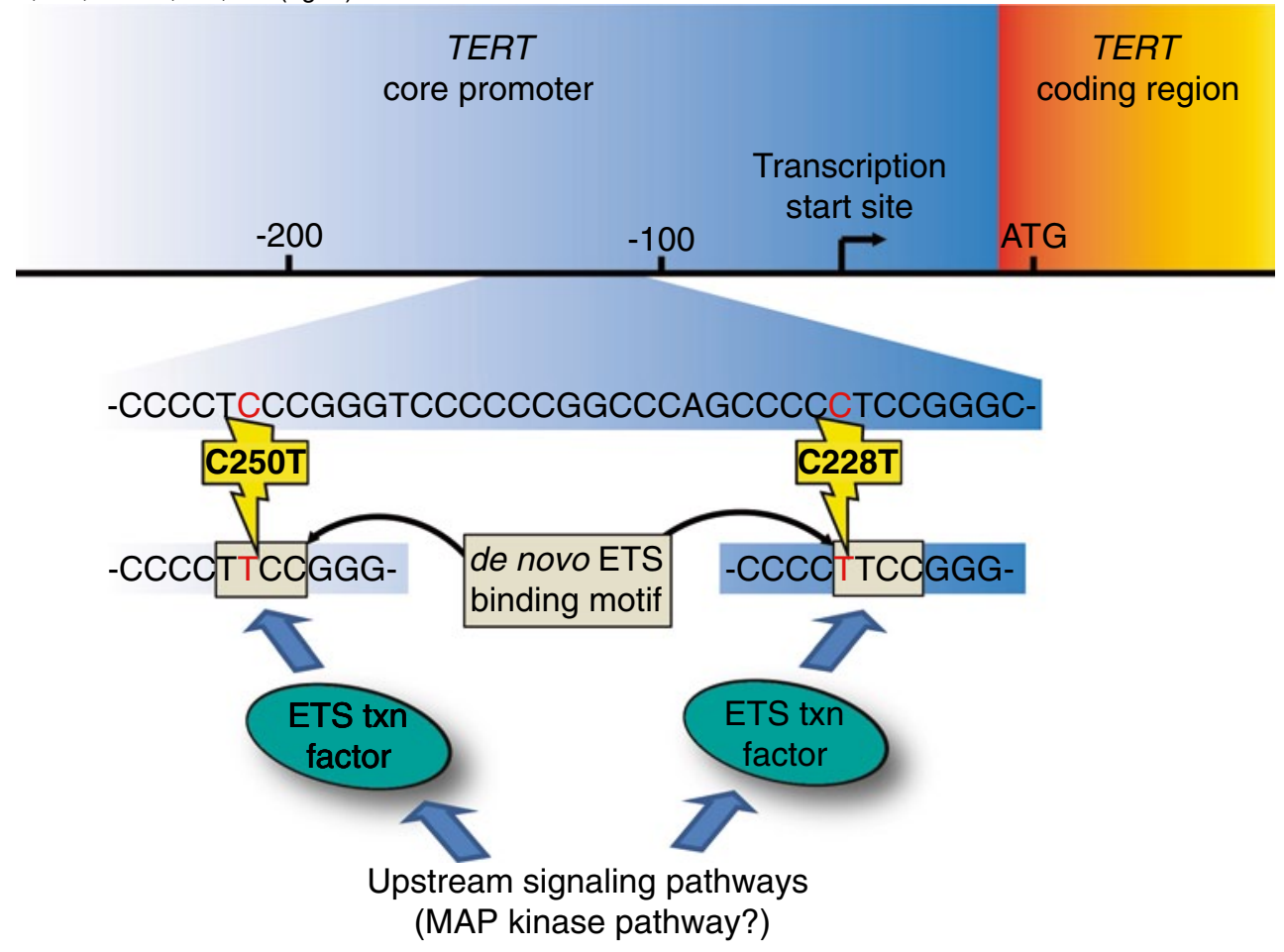

Fig. 1 TERT promoter mutations generate de novo ETS binding sites. The C228T mutation within the TERT promoter occurs $146 \mathrm{bp}$ upstream of the ATG start codon of TERT, at chr5 1,295,228 (hg19). The C250T mutation occurs 126 bp upstream of the ATG start codon of TERT, at chr5 1,295,250. Both mutations generate a de novo

As with gliomas, TERT mutations occurred in distinct subsets of medulloblastomas. The TERT mutations tended to occur in medulloblastomas from older patients, and were particularly frequent among the older patients with medulloblastomas from the SHH (83\%) and WNT (31\%) gene expression-based subgroups. In contrast, the TERT mutations were rare among the Group 3 and 4 tumors $(<5 \%)$.

What is the function of the TERT mutations? Two mutations account for the vast majority of the somatic TERT mutations in CNS and other tumor types. Both alterations are cytosine to thymine $(\mathrm{C}>\mathrm{T})$ transitions and have been termed $\mathrm{C} 228 \mathrm{~T}$ and $\mathrm{C} 250 \mathrm{~T}$ based on their genomic coordinates on chromosome 5. These events occur 124 and 146 base pairs upstream of the ATG start codon of TERT, respectively, as shown in Fig. 1. Both of those alterations generate an identical 11-bp nucleotide motif (5'-CCCCTTCCGGG-3') containing a consensus binding site for E-twenty-six (ETS) transcription factors. Generation of this motif suggests that the mutated promoter gains the ability to recruit transcription factors that might upregulate TERT protein expression. In line with this possibility, the mutated TERT promoter drives higher expression of an experimental reporter gene in cell lines compared to the wild-type sequence, 5'-CCCCTTCCGGG-3', which contains the ETS transcription factor binding motif $5^{\prime}-3^{\prime}$ TCC- $3^{\prime}$. The new ETS motif may recruit transcription factors from the ETS family, some of which are downstream targets of MAP kinase signaling

promoter [7]. Also, tumors containing TERT promoter mutations are correlated with higher TERT mRNA expression than wild-type tumors [1]. Additional rarer mutations have also been discovered in the TERT promoter, including $\mathrm{C} 249 \mathrm{~T}$ and C228A, which do not result in generation of an ETS box per se [9, 10], adding some complexity to the situation. Also, patients with hereditary melanomas harbor TERT promoter mutations at a different position than the mutations that arise in sporadic tumors [5], indicating that germline TERT mutations might have a slightly different functional impact than the somatic TERT promoter mutations.

The TERT mutations allowed delineation of two genetic mechanisms for telomere maintenance among many tumors. The gliomas, including oligodendrogliomas, astrocytomas, and glioblastomas, are a particularly interesting example. While oligodendrogliomas (WHO grade II and III) and primary glioblastomas (WHO grade IV) have been known for years to have activated telomerase, astrocytomas of grades II and III and secondary glioblastomas WHO grade IV seldom have activated telomerase. Instead, these astrocytomas have been found to employ an alternative lengthening of telomeres (ALT) phenotype [4, 11]. 
ALT is a homologous recombination-mediated mechanism of telomere length maintenance that is independent of telomerase activity. Thus, telomerase activation and ALT are two different mechanisms employed by different tumors to maintain their telomeres. Intriguingly, the astrocytomas WHO grade II-III and secondary glioblastomas WHO grade IV with ALT were recently found to harbor mutations in ATRX that are thought to cause or contribute to the ALT phenotype [8]. In contrast, new data indicate that primary glioblastomas and oligodendrogliomas frequently harbor TERT mutations [9, 13]. These results together provide a genetic basis for telomere deregulation in most higher-grade gliomas, with ATRX mutations accounting for ALT in grade II-III astrocytomas and secondary glioblastomas, and TERT promoter mutations accounting for the telomerase activation seen in oligodendrogliomas and primary glioblastomas.

The situation in medulloblastomas, in which the TERT promoter mutations occur mostly in the adult subset of patients even though it is a predominantly pediatric tumor, highlights an important age-based distribution of the mutations. A similar situation is observed among glioblastomas. While TERT mutations are overall frequent among glioblastomas, they almost never occur in pediatric glioblastomas $[9,10]$. Why are the TERT mutations virtually absent from tumors in children? Since telomerase is thought to be active in stem and progenitor cells early in life, this conspicuous age distribution has raised the possibility that childhood tumors may arise from cells that already have activated telomerase and, therefore, do not need to acquire a TERT mutation to aberrantly upregulate telomerase.

The high frequency of TERT mutations, and their association with distinct patient subgroups, raises the possibility that TERT mutations could aid in classification of gliomas and other CNS tumors. This possibility is especially tantalizing because the TERT mutations are relatively unambiguous and could be assayed by determining the sequence of only a few base pairs within the genome. Already, Remke and colleagues [14] have demonstrated a straightforward Taqman-based assay assessing the presence of the two most common TERT mutations. Determining TERT mutation status may be useful for stratification of patients for clinical trials to determine whether specific therapies are effective in different genetic subtypes of tumors. In addition, the mutations may be helpful for prognostication: for instance, those patients harboring tumoral TERT mutations survive longer than other patients among the group of SHH medulloblastomas [14].

Major questions remain in regards to the TERT mutations. Preliminary studies suggest differences in survival between patients with and without TERT mutations for several tumor types [9, 13]. For instance, patients with TERTmutated glioblastomas have a poorer survival than TERT wild-type glioblastomas. However, this effect may reflect the improved survival of patients with $I D H 1$-mutated glioblastomas, who almost always fall into the TERT wild-type group [13]. Thus, it remains to be seen whether TERT status is an independent prognostic indicator among glioblastomas [13].

It is important to note that a subset of adult primary glioblastomas exhibiting telomerase activation seem to lack TERT mutations. What genetic or epigenetic alteration is responsible for telomerase activation in these tumors? In a letter in this issue, Arita and colleagues [2] tested whether adult glioblastomas with upregulated TERT mRNA expression, but no TERT promoter mutation, might have a hypermethylated TERT promoter that could account for increased TERT mRNA expression. In fact, methylation of the TERT promoter had been found to be strongly associated with increased TERT expression in pediatric brain tumors, indicating that methylation, and not mutation, of the TERT promoter can account for TERT upregulation in certain tumors [3]. This finding stood in contrast to the typical role for promoter methylation, in which methylation usually silences expression of the associated gene. In contrast to the situation in pediatric glioblastomas, Arita and coworkers found that adult glioblastomas with high TERT expression, but with a wild-type TERT promoter, did not have increased TERT promoter methylation. This work leaves an open question as to the mechanism behind telomerase activation in the tumors that do not harbor either TERT promoter mutations or TERT promoter hypermethylation.

Further study of the TERT mutations may reveal new therapeutic hypotheses for several deadly types of CNS tumors. Years of study of telomerase as a therapeutic target, long before the discovery of the promoter mutations, has already resulted in several inhibitors of telomerase. These include imetelstat, which has elicited telomere shortening and tumor cell death in animal glioma models [12]. Might TERT mutation status help identify patients who best respond to telomerase-based therapies? Another consideration is that tumors treated with telomerase inhibitors may evolve resistance by developing ALT [6]. If so, combination therapies that also disrupt ALT may ultimately be necessary to target the telomere maintenance pathway in cancer. Finally, generation of ETS transcription factor binding sites by the TERT mutations points towards recruitment of one or more transcription factors to the TERT promoter as a critical step for tumor development. In this way, the discovery of the TERT promoter mutations may point the way towards innovative therapeutic strategies aimed at the molecular pathway upstream of that critical transcription factor or factors. Further research promises to pinpoint the role of TERT promoter mutations in CNS tumor pathogenesis and to lead the way towards improved tumor classification and treatment based on these unique mutations. 
Conflict of interest The authors declare that they have no conflict of interest.

\section{References}

1. Arita H, Narita Y, Fukushima S, Tateishi K, Matsushita Y, Yoshida A, Miyakita Y, Ohno M, Collins VP, Kawahara N, Shibui S, Ichimura K (2013) Upregulating mutations in the TERT promoter commonly occur in adult malignant gliomas and are strongly associated with total 1p19q loss. Acta Neuropathol 126(2):267276. doi:10.1007/s00401-013-1141-6

2. Arita H, Narita Y, Takami H, Fukushima S, Matsushita Y, Yoshida A, Miyakita Y, Ohno M, Shibui S, Ichimura K (2013) TERT promoter mutations rather than methylation are the main mechanism for TERT upregulation in adult gliomas. Acta Neuropathol. doi:10.1007/s00401-013-1203-9

3. Castelo-Branco P, Choufani S, Mack S, Gallagher D, Zhang C, Lipman T, Zhukova N, Walker EJ, Martin D, Merino D, Wasserman JD, Elizabeth C, Alon N, Zhang L, Hovestadt V, Kool M, Jones DT, Zadeh G, Croul S, Hawkins C, Hitzler J, Wang JC, Baruchel S, Dirks PB, Malkin D, Pfister S, Taylor MD, Weksberg R, Tabori U (2013) Methylation of the TERT promoter and risk stratification of childhood brain tumours: an integrative genomic and molecular study. Lancet Oncol 14(6):534-542. doi:10.1016/ s1470-2045(13)70110-4

4. Henson JD, Hannay JA, McCarthy SW, Royds JA, Yeager TR, Robinson RA, Wharton SB, Jellinek DA, Arbuckle SM, Yoo J, Robinson BG, Learoyd DL, Stalley PD, Bonar SF, Yu D, Pollock RE, Reddel RR (2005) A robust assay for alternative lengthening of telomeres in tumors shows the significance of alternative lengthening of telomeres in sarcomas and astrocytomas. Clin Cancer Res 11(1):217-225

5. Horn S, Figl A, Rachakonda PS, Fischer C, Sucker A, Gast A, Kadel S, Moll I, Nagore E, Hemminki K, Schadendorf D, Kumar R (2013) TERT promoter mutations in familial and sporadic melanoma. Science 339(6122):959-961. doi:10.1126/ science. 1230062

6. Hu J, Hwang SS, Liesa M, Gan B, Sahin E, Jaskelioff M, Ding Z, Ying H, Boutin AT, Zhang H, Johnson S, Ivanova E, Kost-Alimova M, Protopopov A, Wang YA, Shirihai OS, Chin L, DePinho RA (2012) Antitelomerase therapy provokes ALT and mitochondrial adaptive mechanisms in cancer. Cell 148(4):651-663. doi:10.1016/j.cell.2011.12.028

7. Huang FW, Hodis E, Xu MJ, Kryukov GV, Chin L, Garraway LA (2013) Highly recurrent TERT promoter mutations in human melanoma. Science 339(6122):957-959. doi:10.1126/ science. 1229259

8. Jiao Y, Killela PJ, Reitman ZJ, Rasheed AB, Heaphy CM, de Wilde RF, Rodriguez FJ, Rosemberg S, Oba-Shinjo SM, Nagahashi Marie SK, Bettegowda C, Agrawal N, Lipp E, Pirozzi C, Lopez G, He Y, Friedman H, Friedman AH, Riggins GJ, Holdhoff
M, Burger P, McLendon R, Bigner DD, Vogelstein B, Meeker AK, Kinzler KW, Papadopoulos N, Diaz LA, Yan H (2012) Frequent ATRX, CIC, and FUBP1 mutations refine the classification of malignant gliomas. Oncotarget 3(7):709-722

9. Killela PJ, Reitman ZJ, Jiao Y, Bettegowda C, Agrawal N, Diaz LA Jr, Friedman AH, Friedman H, Gallia GL, Giovanella BC, Grollman AP, He TC, He Y, Hruban RH, Jallo GI, Mandahl N, Meeker AK, Mertens F, Netto GJ, Rasheed BA, Riggins GJ, Rosenquist TA, Schiffman M, Shih Ie M, Theodorescu D, Torbenson MS, Velculescu VE, Wang TL, Wentzensen N, Wood LD, Zhang M, McLendon RE, Bigner DD, Kinzler KW, Vogelstein B, Papadopoulos N, Yan H (2013) TERT promoter mutations occur frequently in gliomas and a subset of tumors derived from cells with low rates of self-renewal. Proc Natl Acad Sci USA 110(15):6021-6026. doi:10.1073/pnas.1303607110

10. Koelsche C, Sahm F, Capper D, Reuss D, Sturm D, Jones DT, Kool M, Northcott PA, Wiestler B, Bohmer K, Meyer J, Mawrin C, Hartmann C, Mittelbronn M, Platten M, Brokinkel B, Seiz M, Herold-Mende C, Unterberg A, Schittenhelm J, Weller M, Pfister S, Wick W, Korshunov A, von Deimling A (2013) Distribution of TERT promoter mutations in pediatric and adult tumors of the nervous system. Acta Neuropathol. doi:10.1007/ s00401-013-1195-5

11. Langford LA, Piatyszek MA, Xu R, Schold SC Jr, Shay JW (1995) Telomerase activity in human brain tumours. Lancet 346(8985):1267-1268

12. Marian CO, Cho SK, McEllin BM, Maher EA, Hatanpaa KJ, Madden CJ, Mickey BE, Wright WE, Shay JW, Bachoo RM (2010) The telomerase antagonist, imetelstat, efficiently targets glioblastoma tumor-initiating cells leading to decreased proliferation and tumor growth. Clin Cancer Res 16(1):154-163. doi:10.1158/1078-0432.ccr-09-2850

13. Nonoguchi N, Ohta T, Oh JE, Kim YH, Kleihues P, Ohgaki H (2013) TERT promoter mutations in primary and secondary glioblastomas. Acta Neuropathol. doi:10.1007/s00401-013-1163-0

14. Remke M, Ramaswamy V, Peacock J, Shih DJ, Koelsche C, Northcott PA, Hill N, Cavalli FM, Kool M, Wang X, Mack SC, Barszczyk M, Morrissy AS, Wu X, Agnihotri S, Luu B, Jones DT, Garzia L, Dubuc AM, Zhukova N, Vanner R, Kros JM, French PJ, Van Meir EG, Vibhakar R, Zitterbart K, Chan JA, Bognar L, Klekner A, Lach B, Jung S, Saad AG, Liau LM, Albrecht S, Zollo M, Cooper MK, Thompson RC, Delattre OO, Bourdeaut F, Doz FF, Garami M, Hauser P, Carlotti CG, Van Meter TE, Massimi L, Fults D, Pomeroy SL, Kumabe T, Ra YS, Leonard JR, Elbabaa SK, Mora J, Rubin JB, Cho YJ, McLendon RE, Bigner DD, Eberhart CG, Fouladi M, Wechsler-Reya RJ, Faria CC, Croul SE, Huang A, Bouffet E, Hawkins CE, Dirks PB, Weiss WA, Schuller U, Pollack IF, Rutkowski S, Meyronet D, Jouvet A, Fevre-Montange M, Jabado N, Perek-Polnik M, Grajkowska WA, Kim SK, Rutka JT, Malkin D, Tabori U, Pfister SM, Korshunov A, von Deimling A, Taylor MD (2013) TERT promoter mutations are highly recurrent in SHH subgroup medulloblastoma. Acta Neuropathol. doi:10.1007/s00401-013-1198-2 